\title{
Protocol Deviations Supplemental Qualifiers Dataset
}

National Cancer Institute

\section{Source}

National Cancer Institute. Protocol Deviations Supplemental Qualifiers Dataset. NCI

Thesaurus. Code C147206.

A dataset containing supplemental information, specifically non-standard variables, to parent records in the protocol deviations domain. 